\title{
Evapotranspiration management based on the application of SWAT for balancing water consumption: A case study in Guantao, China
}

\author{
Bin LiU ${ }^{1,2, *}$ (1) and Hong GaN ${ }^{1}$ \\ ${ }^{1}$ Department of Water Resources, China Institute of Water Resources and Hydropower Research, 1-A Fuxing \\ Road, Haidian District, Beijing 100 038, People's Republic of China. \\ ${ }^{2}$ Hebei University of Engineering, Handan 056 021, Hebei, People's Republic of China. \\ *Corresponding author. e-mail: liubin820104@163.com
}

MS received 5 April 2017; revised 19 September 2017; accepted 22 September 2017; published online 22 May 2018

Rapid social and economic development results in increased demand for water resources. This can lead to the unsustainable development and exploitation of water resources which in turn causes significant environmental problems. Conventional water resource management approaches, such as supply and demand management strategies, frequently fail to restore regional water balance. This paper introduces the concept of water consumption balance, the balance between actual evapotranspiration (ET) and target ET, and establishes a framework to realize regional water balance. The framework consists of three stages: (1) determination of target ET and actual ET; (2) quantification of the water-saving requirements for the region; and (3) reduction of actual ET by implementing various water saving management strategies. Using this framework, a case study was conducted for Guantao County, China. The SWAT model was utilized to aid in the selection of the best water saving management strategy by comparing the ET of different irrigation methods and crop pattern adjustments. Simulation results revealed that determination of SWAT model parameters using remote sensing ET is feasible and that the model is a valuable tool for ET management. Irrigation was found to have a greater influence on the ET of winter wheat as compared to that of maize, indicating that reduction in winter wheat cultivation is the most effective way to reduce regional ET. However, the effect of water-saving irrigation methods on the reduction of ET was not obvious. This indicates that it would be difficult to achieve regional ET reduction using water-saving irrigation methods only. Furthermore, selecting the best water saving management strategy by relying solely on the amount of reduced ET was insufficient, because it ignored the impact of water conservation measures on the livelihood of the agricultural community. Incorporating these considerations with our findings, we recommend changing the current irrigation method to sprinkler irrigation and replacing $20 \%$ of the winter wheat-maize cultivated area with cotton, as the best strategy to achieve water balance in the study area.

Keywords. Water consumption balance; target evapotranspiration; actual evapotranspiration; SWAT.

\section{Introduction}

Water is one of the most indispensable natural resources for human survival and development
(Vörösmary et al. 2010). Socio-economic development and an increasing population, combined with the effects of climate change, mean 
that water scarcity has become a critical issue that attracts global attention (Frederick and Major 1997; Vörösmary et al. 2000; Forsee and Ahmad 2011; Dawadi and Ahmad 2013; DeNicola et al. 2015). In the past, approaches to managing water resources have focused on increasing the water supply through developing new water diversion, pumping, transfer and storage projects, in order to satisfy increasing water needs (Gleick 1998; Wu et al. 2014). However, water supply management considers water demand as a requirement that must be met, leading to a decrease in natural flows, resource wastage, and pollution problems (Barnett and Pierce 2008; Wang et al. 2011; Pengra 2012). Thus, driven by environmental protection concerns, there is an increasing need for the implementation of water saving measures that focus on the demand side.

Water demand management is an essential complement to supply management, which seeks to make water use more efficient and sustainable through modifying patterns of water demand, lowering water demand itself, and reducing losses during water movement (Brooks 2006). Effective demand management can contribute to a slower increase in water demand, relieving the growing stress on water resources associated with population increases and climate change. However, it is difficult to fundamentally decrease water demand. With the continuous growth in water demand, water supplies in many countries are insufficient to satisfy their current urban, industrial, environmental, and agricultural water requirements (Perry et al. 2009; FAO 2012; Gallopín 2012; UNESCO 2012).

Irrigation plays a crucial role in crop production globally, insofar as approximately $69 \%$ of the world's fresh water withdrawals are used for crop irrigation (FAO 2014). As rapid economic development continues, urban areas are allocated priority over water resources (Beltran 1999; Wang et al. 2001), requiring irrigated agricultural regions to become more efficient in their use of the available water (Jury and Vaux 2006; Rockstrom et al. 2007). Water conservation is often used synonymously with water demand management in irrigation (Russell and Fielding 2010). Conventional irrigation systems mainly rely on engineering measures to improve irrigation efficiency, including the reduction of channel and field leakage, channel return water, and drainage water. These measures are generally thought to conserve more water, and hence make more water available for cities and the environment, as compared to flood irrigation (Ward and Pullido-Velazquez 2008). However, the water saved using these conventional water-saving irrigation technologies cannot all be recognized as real water savings (Davenport and Hagan 1982).

Water conservation measures can be categorized into efficiency and resource measures (Gardner and Stern 1996). Water savings achieved using efficiency measures tend to increase crop yield for the same volume of water consumption. Consequently, due to the pursuit of increased crop production, the absolute volume of water saved using efficiency measures is insignificant. Water savings achieved using resource measures include a recoverable and irrecoverable fraction (Davenport and Hagan 1982). When the conserved water can be reused in other areas or for expanded production, it is considered to be recoverable water. For water resources in water scarce areas, farm efficiency improvements may allow for more irrigated acreage or permit more water intensive crops to be grown, but the volume of recoverable water generally cannot satisfy new water requirements, which increase demand and, consequently, water shortages. Irrecoverable water refers to the amount of water that is consumed by evapotranspiration (ET) and cannot be reused. Reducing the volume of irrecoverable water is the real water saving in a given area. Thus, at the basin or regional level, limiting irrecoverable water depletion, and achieving water balance is critical.

Evapotranspiration is the transport of water from the Earth's surface to the atmosphere, and represents the main depletion of water within a basin or region (Falkenmark and Rockström 2004). Initially, ET was only considered by the field of irrigation research. However, in December 1998, the World Bank proposed ET management as the main factor for maintaining regional water balance in water saving irrigation projects in China. Consequently, ET management expanded from agricultural irrigation to regional water resource management, representing a theoretical leap in water management. Now, ET management receives extensive attention, and is the most important aspect of water management. ET is widely measured and monitored under different land uses and spatial scales. However, little research has been done on the use of ET management to guide structural changes of water use in basins or regions to achieve water balance. A notable exception is the work of Wu et al. (2014), which describes a framework for water resource management based on ET 
at the basin scale, and divides ET management into four steps. This work presents a new approach to water management, but the challenge of how to use the concept to guide the practical application of alternative water management strategies, and quantify their effects on regional ET, needs further study.

This study introduces the concept of water consumption balance, and uses a physically based simulation model, the SWAT model, to assist ET management in Guantao County, China. The study has the following specific objectives: (1) define the steps to achieve regional water balance based on the concept of water consumption balance; (2) assess the capabilities of the SWAT model for regional ET management; and (3) choose the most appropriate water saving management strategy to achieve regional water balance in the study area.

\section{The concept of water consumption balance}

Evapotranspiration, which occurs during processing of water cycle and the utilization of water resources, is considered to be irrecoverable water consumption. According to the principle of water balance, the water balance equation of a region can be expressed as:

$$
E T=P+I-O \pm \Delta V
$$

where $E T$ is evaporation and transpiration of a region, $P$ is precipitation, $I$ and $O$ are water inflows and outflows, respectively, and $\Delta V$ is the variation in water storage. Under average annual conditions, $\Delta V=0$, and the water balance equation (1) is expressed as:

$$
E T_{n}=P+I-O_{n}
$$

which represents the state of the region in a natural state, with humans having a small impact. However, when water resources in a region are excessively utilized, water balance will not be maintained as per equation (2). Under these conditions, the natural flow $O_{n}$ decreases, the water table recedes ( $\Delta V$ is negative), ET increases, and the water balance equation for average annual conditions is as follows:

$$
E T_{a}=P+I-O_{a}-\Delta V_{g}
$$

where $P$ and $I$ are basin precipitation and inflows, $E T_{a}$ and $O_{a}$ are actual ET and inflows under intensive human impacts, and $\Delta V_{g}$ is overexploited groundwater. Assuming regional precipitation and inflows remain constant, equation (3) can be rewritten as:

$$
E T_{a}=E T_{n}+O_{n}-O_{a}-\Delta V
$$

and

$$
\Delta E T=E T_{a}-E T_{n}=O_{n}-O_{a}-\Delta V .
$$

It is apparent that the increased water consumption of a region is contributed of the reduction of runoff and the over-exploitation of groundwater. Considering the sustainable utilization of a water resource, it is necessary to preserve the environmental flow (so that $O_{a}$ is not less than river ecological flows) and not to overexploit ground water $\left(\Delta V_{g}=0\right)$. The $\Delta E T$ cannot be increased indefinitely. As such, the ET from a region must be limited to a single value, called the target ET $\left(\mathrm{ET}_{\mathrm{tar}}\right)$. When actual ET $\left(\mathrm{ET}_{\mathrm{a}}\right.$ or $\left.\mathrm{ET}_{\mathrm{act}}\right)$ is larger than $\mathrm{ET}_{\mathrm{tar}}$, the utilization of water resources in the region is unsustainable, and it becomes necessary to take water-saving measures to reduce water consumption, so that the $\mathrm{ET}_{\text {act }}$ does not exceed the $\mathrm{ET}_{\mathrm{tar}}$. Thus, the concept of water consumption balance refers to the balance between $\mathrm{ET}_{\text {act }}$ and $\mathrm{ET}_{\mathrm{tar}}$.

\subsection{Confirmation of target ET}

Target ET $\left(\mathrm{ET}_{\mathrm{tar}}\right)$ is the maximum allowable value for water consumption in a region to sustainably maintain water resources. This value should incorporate future regional socioeconomic development, non-continuous overdrafts of groundwater, and ensure that ecological flow in the river system can be preserved. The confirmation of $\mathrm{ET}_{\mathrm{tar}}$ should be based on formula (2), in which precipitation can be measured at hydrological and meteorological stations, and inflows are measured at hydrological stations or major control points. Inflows include surface/underground runoff originating outside the region, and water that has been transferred through water diversion projects. Outflows include surface/underground runoff and transferred water, which should consider downstream ecological and environmental water demands. 
When water balance is achieved, commonly, the outflows exceed inflows, and ET is lower than precipitation. In contrast, when water balance is not achieved, the opposite is generally true. If outflows are equal to inflows, with consideration given to minimum river ecological demands, then regional water resources can be maintained sustainably as $\mathrm{ET}_{\text {tar }}$ does not exceed mean annual precipitation. Therefore, $\mathrm{ET}_{\mathrm{tar}}$ should equal mean annual precipitation. When the water supply in a region includes transferred water, $\mathrm{ET}_{\mathrm{tar}}$ should also include this volume of water.

\subsection{Determination of actual ET}

Actual ET $\left(\mathrm{ET}_{\mathrm{act}}\right)$ is the volume of water consumed in a region under the influence of the natural water cycle and artificial water resource utilization. The ET of a region includes ET from domestic, industrial, environmental, agricultural, and other sources (such as the ET from non-cultivated land).

$$
\begin{aligned}
E T_{\mathrm{act}}= & E T_{\mathrm{dom}}+E T_{\mathrm{ind}}+E T_{\mathrm{env}} \\
& +E T_{\mathrm{agr}}+E T_{\mathrm{oth}} .
\end{aligned}
$$

The various ET components in this equation can be obtained by direct calculation and indirect estimation. Due to the complexity of domestic ET $\left(\mathrm{ET}_{\mathrm{dom}}\right)$ and industrial ET $\left(\mathrm{ET}_{\mathrm{ind}}\right)$, they are estimated indirectly. $\mathrm{ET}_{\mathrm{dom}}$ can be estimated using population and per capita water consumption data, while $\mathrm{ET}_{\text {ind }}$ can be calculated using production data and the water consumption per unit of product (Wu et al. 2014). The environmental ET $\left(\mathrm{ET}_{\mathrm{env}}\right)$, agricultural ET $\left(\mathrm{ET}_{\mathrm{agr}}\right)$ and other ET $\left(\mathrm{ET}_{\mathrm{oth}}\right)$ can be obtained using hydrological model simulations (Abbott et al. 1986; Beasley and Hyggins 1995; Arnold et al. 1996) or remote sensing ( $\mathrm{Su}$ 2002; Bastiaanssen et al. 2005; Allen et al. 2007; Wu et al. 2012).

\subsection{Reduction of actual ET while aiming for target ET}

In areas affected by water shortages, reducing actual ET to the target ET can be achieved by decreasing excessive domestic, industrial, environmental, and agricultural water consumption. In conjunction with socioeconomic development, $\mathrm{ET}_{\mathrm{dom}}, \mathrm{ET}_{\mathrm{ind}}$ and $\mathrm{ET}_{\mathrm{env}}$ will inevitably rise. Thus, decreasing $\mathrm{ET}_{\mathrm{agr}}$ is the primary means to reduce $\mathrm{ET}_{\mathrm{act}}$. Reducing agricultural water consumption can be achieved by implementing engineering and agronomic water-saving measures. Engineering water-saving measures focus on reducing the volume of water extraction, as well as reducing water consumption from exposed water surfaces, water logged areas, and the excessive irrigation of farmland. Agronomic water-saving measures are the most effective methods to reduce water consumption, and these include straw mulching, conservation tillage, changing crop varieties, and so on (Blanke et al. 2007). In this study, we model scenarios using different irrigation methods and crop pattern adjustments to achieve water consumption balance targets in the region by reducing excessive agricultural water consumption.

In areas where water for irrigation purposes predominates water use, domestic and industrial water consumption is often ignored for simplicity. Reducing $\mathrm{ET}_{\text {act }}$ to $\mathrm{ET}_{\text {tar }}$ requires the assistance of water management models, which are used to select the best water saving management strategies to satisfy regional water-saving requirements through the comparison of various water management scenarios.

\section{Case study}

\subsection{The SWAT model}

A number of distributed watershed models, such as MIKE SHE (Abbott et al. 1986), ANSWERS (Beasley and Hyggins 1995), IHDM (Beven et al. 1987) and SWAT (Arnold et al. 1996), have been used for water resources management. Of these models, the physically based SWAT model has been widely used for assessing the impacts of different land use patterns and water resource management strategies on watershed hydrological cycles, due to its many distinctive features (Ritchie 1972; Su et al. 2003; Holvoet et al. 2007; Van Liew et al. 2007; Cao et al. 2009; Zhang et al. 2010). SWAT subdivides a catchment into subbasins and further divides them into individual hydrologic response units (HRUs) as homogeneous blocks with respect to land use, soil properties and management. However, the ARCGIS interface of the SWAT model that pre-processes the digital elevation model (DEM) data cannot automatically extract the river network from the DEM of the plain. Consequently, in this study, the subwatersheds and HRUs were manually divided into 69 and 483 units respectively, according to a DEM, 


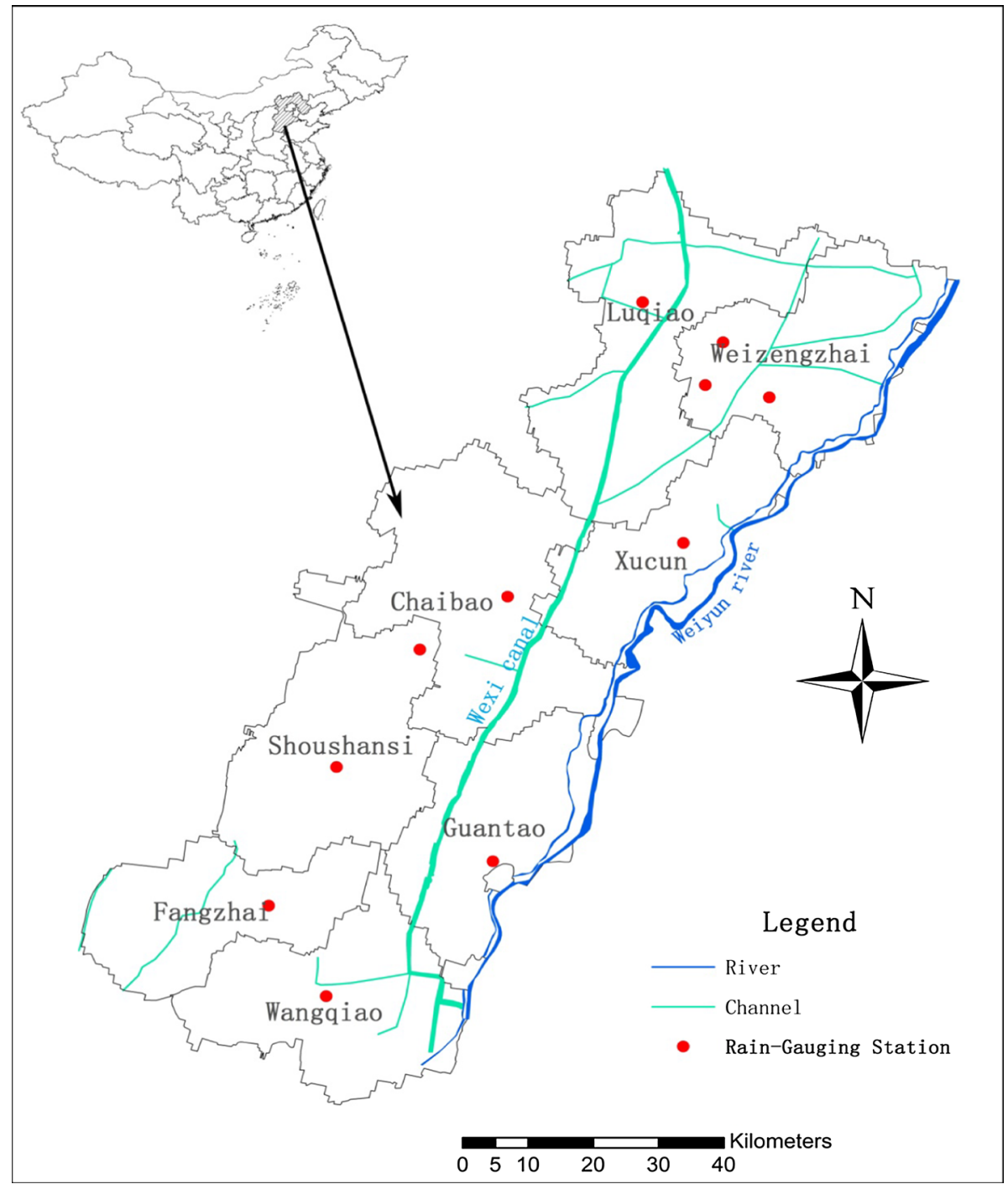

Figure 1. Map of Guantao County with the location of rain-gauging stations marked.

soil, and land use maps. The Penman-Monteith method was selected to estimate the ET in this model (Neitsch et al. 2005; Gao et al. 2008).

\subsection{Study area}

Guantao County covers a total area of $456.3 \mathrm{~km}^{2}$ and is located in the Haihe River Basin, between $26^{\circ} 27^{\prime}-36^{\circ} 47^{\prime} \mathrm{N}$ and $115^{\circ} 06^{\prime}-115^{\circ} 28^{\prime} \mathrm{E}$ in northeastern China (figure 1). Regional terrain is relatively flat and gently levels-off from the SW to the NE. There are no rivers traversing Guantao County, however, the Weiyun River delineates most of the eastern boundary of the county, and the artificial diversion channel, the Wexi Canal, flows through the region from south to north. Guantao County is situated in a semi-humid to semi-arid climatic zone. The annual average temperature is approximately $13.4^{\circ} \mathrm{C}$, and the mean average precipitation is $549.4 \mathrm{~mm}$. The precipitation is uneven in spatial and temporal distribution, with more than $60 \%$ of the precipitation occurring during June-September. The county has 29,000 hectares of irrigated land area, much of which is used to cultivate the crops of winter wheat and maize. More than $89 \%$ of the region's water consumption is used for agricultural irrigation. Due to a serious shortage of surface water and increasing water demand driven by rapid economic development, groundwater has become overexploited in the region. Groundwater declined from a depth of $14.9 \mathrm{~m}$ in 1994 to $23.0 \mathrm{~m}$ in 2012 , equating to an annual average fall in groundwater levels of 0.45 $\mathrm{m}$. Resolving the continuous overexploitation of groundwater is an urgent requirement for the local authorities. 
Table 1. SWAT parameters ranked in order of sensitivity to ET.

\begin{tabular}{llc}
\hline Parameter & \multicolumn{1}{c}{ Definition } & Rank \\
\hline ESCO.hru & Soil evaporation compensation factor & 1 \\
SOL_AWC.sol & Available water capacity of the soil layer & 2 \\
CN2.mgt & SCS runoff curve number & 3 \\
EPCO.hru & Plant uptake compensation factor & 4 \\
CANMX.hru & Maximum canopy storage & 5 \\
SOL_K.sol & Saturated hydraulic conductivity & 6 \\
GW_REVAP.gw & Groundwater revap coefficient & 7 \\
GW_DELAY.gw & The delay time of groundwater & 8 \\
\hline
\end{tabular}

\subsection{Model inputs and outputs}

The SWAT model requires a variety of inputs. To establish the model, the following datasets were prepared: (1) DEM $(1 \times 1 \mathrm{~km})$ provided by the Haihe River Water Conservancy Commission, MWR; (2) 1:10,000 scale land-use map (2000) provided by the government of Guantao County; (3) a 1:100,000 scale soil map generated from the Hebei Soil Handbook; (4) daily climate data (precipitation, wind speed, relative humidity, maximum and minimum air temperature and solar radiation) time series from 2001 to 2005 provided by the Guantao Bureau of Meteorology; and (5) monthly ET data from 2002 to 2005 produced by the ETWatch model (Wu et al. 2008).

\subsection{Model calibration and validation}

The model must be calibrated and validated using a long series of observed data, before it can be used to study the impact of various management scenarios. In this paper, a warm-up period from January 1, 2001 to December 31, 2001was set for the model, allowing state variables to assume realistic initial values for the calibration period. The model was then calibrated using remote sensing derived ET data from January 2002 to December 2003, and the remaining ET data from January 2004 to December 2005 were used as the validation period.

Statistical measures were used to evaluate model performance (Santhi et al. 2006; Moriasi et al. 2007). In this study, Nash-Sutcliffe efficiency (NSE; Nash and Sutcliffe 1970), coefficient of determination $\left(R^{2}\right)$, and root mean square error (RMSE; Yang et al. 2009; Singh et al. 2010) were used

$$
\begin{aligned}
& \mathrm{NSE}= \\
& \frac{\sum_{i=1}^{T}\left(E T_{o b, t}-\overline{E T}_{o b}\right)^{2}-\sum_{i=1}^{T}\left(E T_{o b, t}-E T_{s, t}\right)^{2}}{\sum_{i=1}^{T}\left(E T_{o b, t}-\overline{E T}_{o b}\right)^{2}}
\end{aligned}
$$

$$
\begin{aligned}
& R^{2}= \\
& {\left[\frac{\sum_{i=1}^{T}\left(E T_{o b, t}-E T_{o b}\right)\left(E T_{s, t}-E T_{s}\right)}{\sqrt{\sum_{i=1}^{T}\left(E T_{o b, t}-\overline{E T}_{o b}\right)^{2} \sum_{i=1}^{T}\left(E T_{s, t}-\overline{E T}_{s}\right)^{2}}}\right]^{2}} \\
& R M S E=\sqrt{\frac{1}{T} \sum_{i=1}^{T}\left(E T_{o b, t}-E T_{s, t}\right)^{2}}
\end{aligned}
$$

where $E T_{o b, t}$ and $E T_{s, t}$ are the observed and simulated data values at time unit $t$, respectively, and $t=1,2, \ldots, T ; \overline{E T}_{o b}$ and $\overline{E T}_{s}$ are the mean values for the total evaluation period. $T$ is the total number of observations.

\subsection{Parameter sensitivity}

There are many parameters that influence the ET process in the SWAT model, and as such, analyzing parameter sensitivity is an important step in understanding the performance of the model. The parameter sensitivity analysis helped to reduce parameter dimension and time spent in the model calibration period. In SWAT, the method Latin Hypercube One-factor-At-a-Time (LH-OAT) was used for sensitivity analysis (Griensven 2005). Through the parameter sensitivity analysis, we selected the eight most sensitive parameters (ESCO, SOL_AWC, CN2, EPCO, CANMX, SOL_K, GW_REVA, GW_DELAY), and then manually adjusted these parameters. The parameter sensitivity results, ranked from most to least sensitive, are listed in table 1.

\subsection{Scenarios description}

After calibration and validation, the SWAT model can be used to analyze the impacts of different irrigation methods and crop pattern adjustments on regional ET. For each scenario, local agronomic practices were adopted and kept constant. 
Table 2. The volume of water used per irrigation and irrigation frequency under the three irrigation methods.

\begin{tabular}{lccccc}
\hline & \multicolumn{2}{c}{ Wheat-maize } & & \multicolumn{2}{c}{ Cotton } \\
\cline { 2 - 3 } Irrigation method & $\begin{array}{c}\text { Volume of water per } \\
\text { irrigation }(\mathrm{mm})\end{array}$ & $\begin{array}{c}\text { Irrigation } \\
\text { frequency }\end{array}$ & & $\begin{array}{c}\text { Volume of water per } \\
\text { irrigation }(\mathrm{mm})\end{array}$ & $\begin{array}{c}\text { Irrigation } \\
\text { frequency }\end{array}$ \\
\hline $\begin{array}{l}\text { Ditch plus white plastic } \\
\text { pipe (D+P) }\end{array}$ & 83 & 5 & 83 & 2 \\
$\begin{array}{l}\text { Low pressure pipe } \\
\text { Sprinkler }\end{array}$ & 66 & 5 & 66 & 2 \\
\end{tabular}

Note: The five irrigation dates for winter wheat-maize are March 10, April 20, June 15, July 15, and October 10. The two irrigation dates for cotton are April 22 and June 8.

Table 3. Detailed descriptions of the water management scenarios.

\begin{tabular}{|c|c|c|c|}
\hline $\begin{array}{l}\text { Scenario } \\
\text { no. }\end{array}$ & Irrigation method & Crop pattern adjustments & Objective of scenario analysis \\
\hline S1 & $(\mathrm{D}+\mathrm{P})$ & Maintain the status quo & Effects of irrigation on ET \\
\hline $\mathrm{S} 2$ & Low pressure pipe & Maintain the status quo & \\
\hline S3 & Sprinkler & Maintain the status quo & \\
\hline $\mathrm{S} 4$ & $(\mathrm{D}+\mathrm{P})$ & $\mathrm{T} 1$ & Effects of crop pattern adjustment on ET \\
\hline S5 & & $\mathrm{T} 2$ & \\
\hline S6 & & T3 & \\
\hline S7 & Low pressure pipe & $\mathrm{T} 1$ & Water management scenarios comparison \\
\hline $\mathrm{S} 8$ & & $\mathrm{~T} 2$ & \\
\hline S9 & & T3 & \\
\hline $\mathrm{S} 10$ & & $\mathrm{~T} 4$ & \\
\hline S11 & & T5 & \\
\hline $\mathrm{S} 12$ & & T6 & \\
\hline $\mathrm{S} 13$ & Sprinkler & $\mathrm{T} 1$ & Water management scenarios comparison \\
\hline $\mathrm{S} 14$ & & $\mathrm{~T} 2$ & \\
\hline $\mathrm{S} 15$ & & T3 & \\
\hline $\mathrm{S} 16$ & & $\mathrm{~T} 4$ & \\
\hline $\mathrm{S} 17$ & & T5 & \\
\hline $\mathrm{S} 18$ & & T6 & \\
\hline
\end{tabular}

In this study, three irrigation methods including ditch plus white plastic pipe $(\mathrm{D}+\mathrm{P})$ irrigation, low pressure pipe irrigation, and sprinkler irrigation were simulated to analyze the effects of irrigation on ET. The D $+\mathrm{P}$ irrigation method has been widely used throughout Guantao County, and as such represents the current irrigation scheme of the region. Low pressure pipe irrigation and sprinkler irrigation are two water-saving irrigation methods implemented in the scenarios analysis, which reduced irrigation water by 20 and $40 \%$, respectively, over $\mathrm{D}+\mathrm{P}$. The volume of water used per irrigation and the irrigation frequency under the three irrigation methods are shown in table 2 (Agricultural Bureau of Guantao County). During predictive simulations, six crop pattern adjustment modes were implemented for the different irrigation methods. Details of the six adopted crop pattern adjustment modes are given as:

T1. Winter wheat-maize planting area decreased by $10 \%$.

T2. Winter wheat-maize planting area decreased by $20 \%$.

T3. Winter wheat-maize planting area decreased by $30 \%$.

T4. Winter wheat-maize planting area decreased by $10 \%$ and replaced with cotton.

T5. Winter wheat-maize planting area decreased by $20 \%$ and replaced with cotton.

T6. Winter wheat-maize planting area decreased by $30 \%$ and replaced with cotton.

According to the analysis, there were a total of 18 scenarios used to analyze the impact of different water saving management strategies on ET. 
Table 4. The fitted values after calibration of sensitive parameters.

\begin{tabular}{lllc}
\hline Parameter & Final value & Parameter & Final value \\
\hline ESCO & 0.127 & CANMX & 10 \\
SOL_AWC & $0.10-0.11$ & SOL_K & $0.35-173.20$ \\
CN2 & 71 & GW_REVAP & 0.2 \\
EPCO & 0.175 & GW_DELAY & 30
\end{tabular}

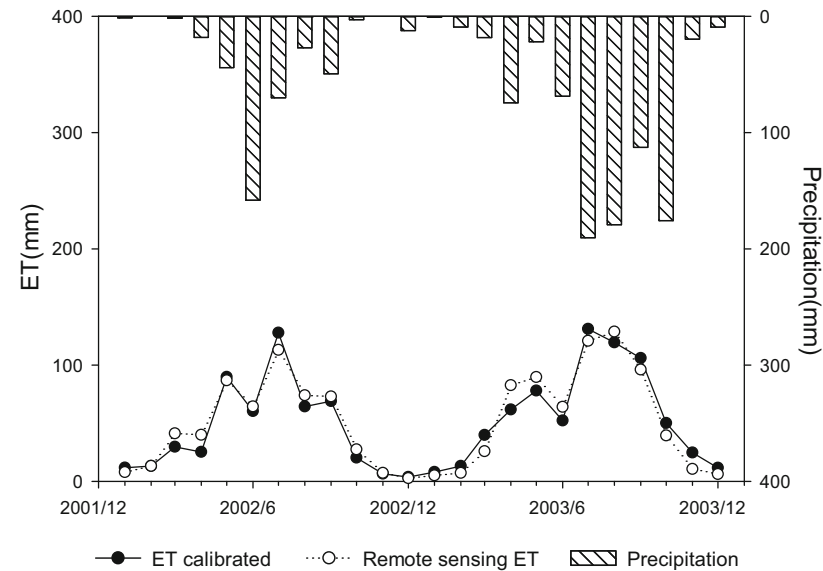

Figure 2. Comparison between remote sensing ET and calibrated ET during 2002-2003.

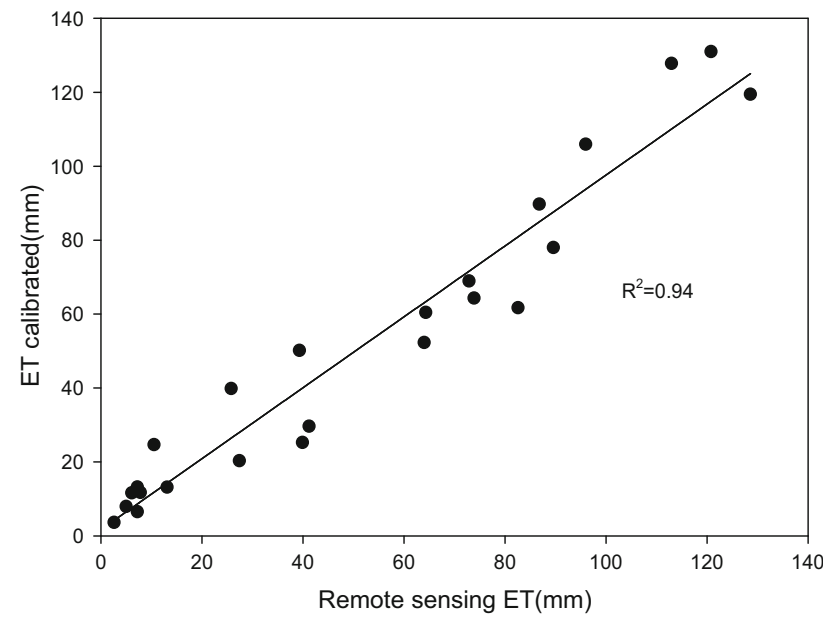

Figure 3. Linear regression between remote sensing ET and calibrated ET during 2002-2003.

Detailed descriptions of the scenarios are given in table 3.

\section{Results and discussion}

\subsection{Calibration and validation of $S W A T$}

The results of the sensitivity analysis are given in table 4. CN2, EPCO, ESCO, CANMX and soil variables were the most sensitive parameters, and

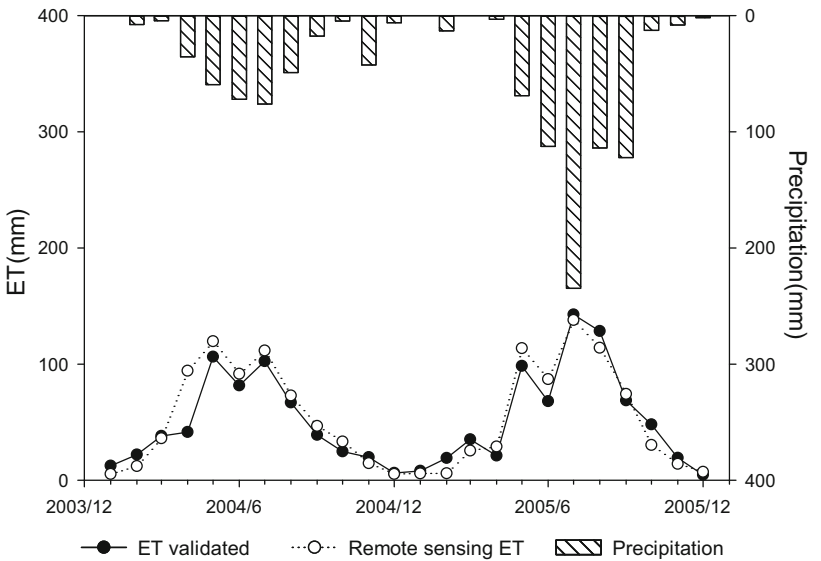

Figure 4. Comparison between remote sensing ET and validated ET during 2004-2005.

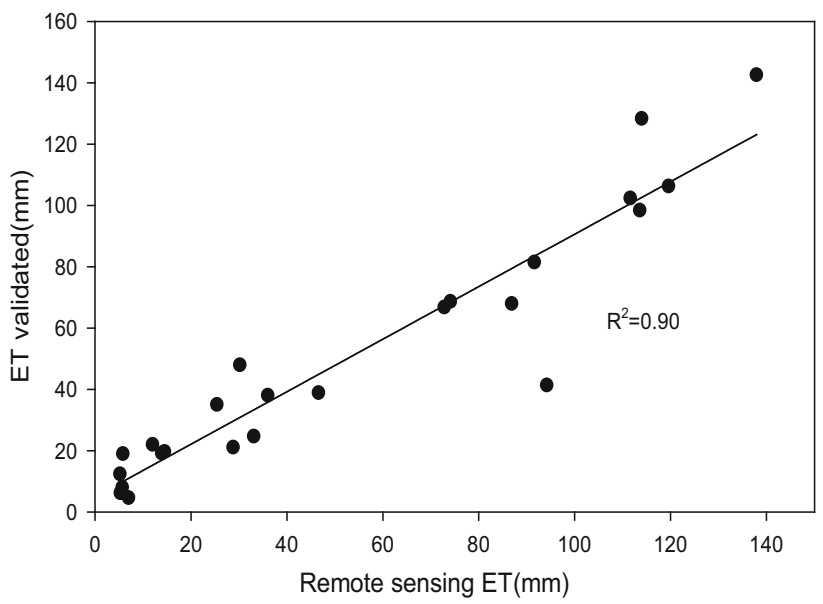

Figure 5. Linear regression between remote sensing ET and validated ET during 2004-2005.

it is apparent that regional ET is mainly affected by surface runoff, soil type and vegetation species.

The comparison between calibrated ET and remotely sensed ET is shown in figure 2, and confirms that the calibration results during the year 2002-2003 matched reasonably well with the remotely sensed ET. A linear regression analysis of the remotely sensed ET and the simulated ET is shown in figure 3, which generated a coefficient of determination $\left(R^{2}\right)$ of 0.94. Additionally, the Nash-Sutcliffe efficiency (NSE) and root mean square error (RMSE) values from the calibration were calculated as 0.94 and $9.89 \mathrm{~mm}$, respectively, indicating that the SWAT model parameters were optimized. A good agreement between simulated values and remotely sensed values was also achieved during the validation results. The values of $R^{2}$, NSE, RMSE were $0.90,1.0$ and $14.5 \mathrm{~mm}$, respectively, for the year 2004 2005. It is apparent from figures (2-5) that the 
Table 5. Simulated ET of D+P irrigation (S1), low pressure pipe irrigation (S2) and sprinkler irrigation (S3) $(\mathrm{mm})$.

\begin{tabular}{lccccc}
\hline Scenarios & 2002 & 2003 & 2004 & 2005 & Average \\
\hline S1 & 521.2 & 695.5 & 560.1 & 660.7 & 609.4 \\
S2 & 511.9 & 692.7 & 549.9 & 655.6 & 602.5 \\
S3 & 483.8 & 678.7 & 524.4 & 639.8 & 581.7 \\
\hline
\end{tabular}

SWAT simulated ET is basically consistent with the remotely sensed ET, that the SWAT performed very well in predicting ET, and is thus useable in a variety of management and planning simulations.

\subsection{Effect of different water management scenarios on ET}

\subsubsection{Effects of irrigation on ET}

Irrigation had a great impact on the regional hydrological cycle, especially on the accurate simulation of ET. In order to elucidate the effect of irrigation on water balance, three different scenarios, including $\mathrm{D}+\mathrm{P}$ irrigation ( $\mathrm{S} 1$ ), low pressure pipe irrigation (S2) and sprinkler irrigation (S3), were simulated. The results of the simulations are shown in table 5, which reveal that low-pressure pipe irrigation and sprinkler irrigation reduced ET by 1.12 and $4.55 \%$, respectively, over the $\mathrm{D}+\mathrm{P}$ irrigation method. Low pressure pipe irrigation and sprinkler irrigation could save 20 and $40 \%$ water, respectively, over the $\mathrm{D}+\mathrm{P}$ irrigation method. However, the amount of water saving only refers to the reduction in water extraction, because ET did not show the same decreasing tendency, indicating that the relationship between reduced water extraction and declining ET is not proportional. This can be attributed to the fact that low-pressure pipe irrigation and sprinkler irrigation only reduce the volume of water loss relative to $\mathrm{D}+\mathrm{P}$ irrigation during the process of transpiration. Because a component of the irrigation water from $\mathrm{D}+\mathrm{P}$ irrigation returns to groundwater through leakage, there is little overall difference in ET between the three irrigation patterns. Consequently, the effect of low-pressure pipe irrigation and sprinkler irrigation on ET is not very significant. Put simply, water-saving irrigation methods are not very effective in reducing ET.

Furthermore, although the effect of winter wheat irrigation on ET is obvious, there is little effect on ET during the maize growth period. In order to reveal the effect of irrigation on ET, the 43rd HRU (an area of $3.5 \mathrm{~km}^{2}$ ) is examined in greater detail. A winter wheat-maize rotation is implemented, and two scenarios, S1 and S3 are simulated. The results are shown in figure 6 , which highlight that the effect of irrigation on the ET of winter wheat, when turning green to mature, was significant, but the effect of irrigation on the ET of maize was very small. For winter wheat, S3 uses less irrigation water as compared to $\mathrm{S} 1$ by $40 \%$, and ET is reduced by $5.8 \%$. For maize, the reduction in irrigation water is the same (40\%), however the reduction in ET is only $1.9 \%$. This discrepancy exists because the growth period for maize coincides with the region's rainy season, when demand for irrigation is low, while the growing season for winter wheat is dry, and the dependence on irrigation is higher.

\subsubsection{Effects of crop pattern adjustments on ET}

Crop pattern adjustments can alter the hydrologic response by changing the land cover and land use across watersheds or regions. Quantifying the impact of crop pattern adjustments on watershed hydrology was one of the important prerequisites for the scenario settings. In this study, scenarios in which the winter wheat-maize planting area was decreased by 10, 20 and $30 \%$ were simulated. The results of the simulations are shown in table 6 , and it is apparent that ET reductions caused by crop pattern adjustments in the wet years were smaller than in the dry years. In dry years, when precipitation was low, and crop growth mainly depended on irrigation. Consequently, crop pattern adjustment could greatly reduce the volume of water required for irrigation and the corresponding ET. Conversely, in wet years, irrigation demand was small. Precipitation could meet the majority of crop water requirements, and as such the impact of crop pattern adjustments to reduce irrigation water and the corresponding ET was not significant. This indicates that, in arid to semi-arid areas, where irrigation predominates, crop pattern adjustment is one of the most effective water saving methods.

\subsection{Effect of different water management scenarios on surface runoff and groundwater recharge}

Different irrigation methods and crop pattern adjustments not only affect regional ET, but also have an influence on other hydrological variables. In this paper, based on the above analysis of 


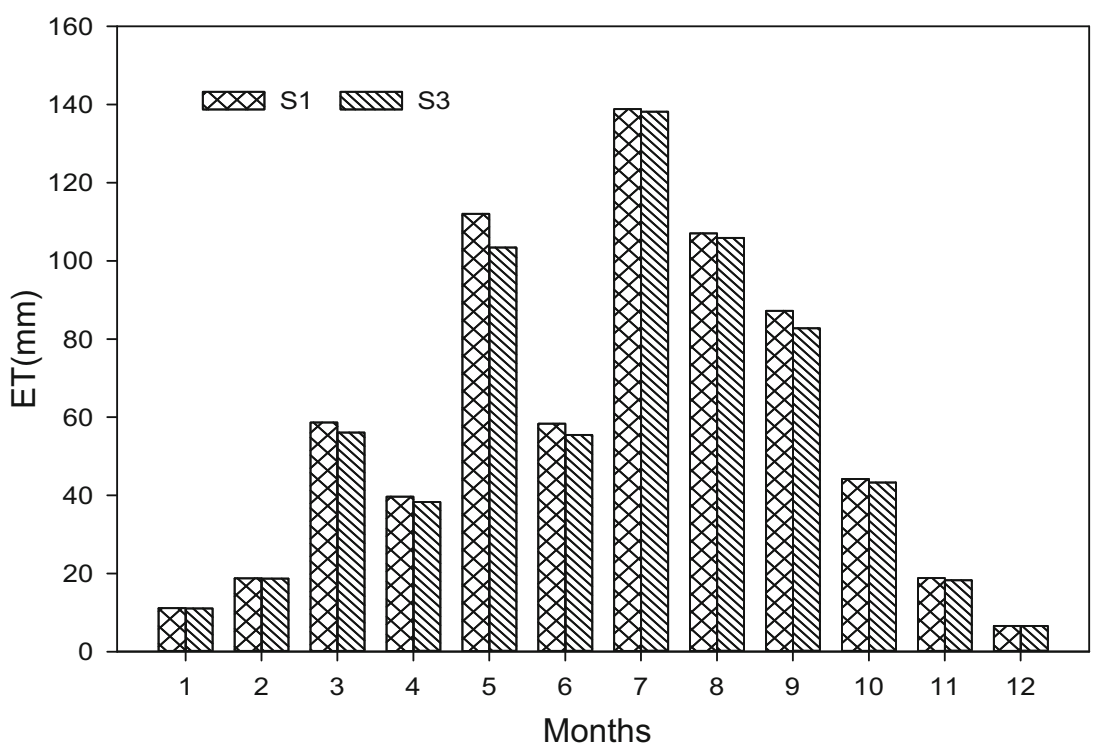

Figure 6. Comparison of monthly average ET values (2002-2005) under scenarios S1 and S3.

Table 6. ET and impacts of decreasing winter wheat-maize planting area.

\begin{tabular}{|c|c|c|c|c|c|c|c|c|}
\hline \multirow[b]{2}{*}{ Year } & \multirow{2}{*}{$\begin{array}{c}\text { Precipitation } \\
\mathrm{mm}\end{array}$} & \multirow{2}{*}{$\begin{array}{c}\mathrm{S} 1 \\
\mathrm{~mm}\end{array}$} & \multicolumn{2}{|c|}{$\mathrm{S} 4$} & \multicolumn{2}{|c|}{ S5 } & \multicolumn{2}{|c|}{ S6 } \\
\hline & & & $\mathrm{mm}$ & $\%$ & $\mathrm{~mm}$ & $\%$ & $\mathrm{~mm}$ & $\%$ \\
\hline 2002 & 384.8 & 521.2 & 507.0 & -2.7 & 492.5 & -5.5 & 478.2 & -8.3 \\
\hline 2003 & 880.0 & 695.5 & 688.4 & -1.0 & 681.3 & -2.0 & 674.2 & -3.1 \\
\hline 2004 & 374.6 & 560.1 & 547.3 & -2.3 & 534.2 & -4.6 & 521.3 & -6.9 \\
\hline 2005 & 689.6 & 660.7 & 652.5 & -1.2 & 644.1 & -2.5 & 635.9 & -3.8 \\
\hline
\end{tabular}

ET, the impact of different water management scenarios on regional surface runoff and groundwater recharge is considered. These results can be seen in tables 7 and 8. It is apparent that surface runoff is declining as water savings increase; for example, from $\mathrm{S} 1$ to $\mathrm{S} 3$. This can be attributed to the fact that, as water savings increase, there is less ineffective irrigation water discharged, and consequently lower soil moisture content. The same level of precipitation onto drier soil will therefore produce less surface runoff.

Using the same irrigation mode, as the irrigated area gradually reduces, surface runoff shows an increasing trend. This is due to the lack of crop interception, as shown in scenarios S4-S6, S7-S9, and S13-S15. However, when the irrigated area of winter wheat-maize is replaced with cotton, the effect of crop interception increases and the surface runoff is gradually reduced. This is demonstrated by $\mathrm{S} 7$ vs. S10, and $\mathrm{S} 13$ vs. S16.

Generally, groundwater recharge is inversely related to surface runoff. For example, S4-S6, S7S9, and S13-S15 highlight that, when the irrigated area decreases and the same irrigation method
Table 7. Simulated surface runoff under different water management scenarios $(\mathrm{mm})$.

\begin{tabular}{lrrrrr}
\hline Scenarios & 2002 & 2003 & 2004 & 2005 & Average \\
\hline S1 & 31.6 & 137.0 & 7.0 & 94.9 & 67.6 \\
S2 & 30.0 & 136.4 & 6.1 & 93.6 & 66.5 \\
S3 & 27.5 & 135.1 & 4.3 & 91.1 & 64.5 \\
S4 & 32.4 & 140.5 & 7.0 & 97.7 & 69.4 \\
S5 & 33.1 & 144.1 & 7.0 & 100.6 & 71.2 \\
S6 & 33.9 & 147.7 & 7.0 & 103.5 & 73.0 \\
S7 & 30.8 & 139.4 & 6.1 & 90.2 & 66.6 \\
S8 & 31.6 & 143.1 & 6.1 & 93.7 & 68.6 \\
S9 & 32.3 & 146.7 & 6.1 & 97.0 & 70.5 \\
S10 & 32.8 & 134.0 & 6.8 & 90.0 & 65.9 \\
S11 & 34.0 & 136.3 & 7.1 & 92.6 & 67.5 \\
S12 & 35.6 & 136.6 & 7.5 & 95.1 & 68.7 \\
S13 & 28.3 & 136.6 & 4.3 & 86.7 & 64.0 \\
S14 & 29.1 & 140.5 & 4.3 & 90.3 & 66.0 \\
S15 & 29.8 & 144.3 & 4.3 & 93.7 & 68.0 \\
S16 & 30.0 & 131.9 & 4.7 & 86.5 & 63.3 \\
S17 & 30.8 & 133.4 & 4.8 & 88.5 & 64.4 \\
S18 & 32.4 & 134.4 & 5.1 & 91.3 & 65.8 \\
\hline
\end{tabular}

is used, the area of bare land increases, and the recharge of groundwater decreases, which is the 
Table 8. Simulated groundwater recharge under different water management scenarios $(\mathrm{mm})$.

\begin{tabular}{lrrrrc}
\hline Scenarios & 2002 & 2003 & 2004 & 2005 & Average \\
\hline S1 & 15.7 & 104.7 & 2.9 & 57.4 & 45.2 \\
S2 & 13.4 & 103.8 & 1.9 & 55.0 & 43.5 \\
S3 & 10.6 & 103.3 & 0.2 & 49.7 & 41.0 \\
S4 & 14.4 & 98.3 & 2.6 & 52.7 & 42.0 \\
S5 & 13.1 & 91.7 & 2.3 & 47.8 & 38.7 \\
S6 & 11.8 & 85.3 & 2.1 & 43.0 & 35.5 \\
S7 & 12.3 & 95.5 & 1.7 & 33.7 & 35.8 \\
S8 & 11.2 & 89.2 & 1.5 & 31.0 & 33.2 \\
S9 & 10.1 & 83.0 & 1.3 & 28.2 & 30.7 \\
S10 & 12.6 & 95.9 & 1.7 & 34.2 & 36.1 \\
S11 & 12.0 & 92.7 & 1.6 & 32.8 & 34.8 \\
S12 & 11.3 & 88.0 & 1.5 & 30.8 & 32.9 \\
S13 & 9.8 & 89.6 & 0.2 & 31.0 & 32.6 \\
S14 & 8.9 & 84.0 & 0.2 & 28.5 & 30.4 \\
S15 & 8.1 & 78.5 & 0.1 & 26.1 & 28.2 \\
S16 & 10.1 & 90.8 & 0.2 & 31.7 & 33.2 \\
S17 & 9.6 & 88.1 & 0.2 & 30.5 & 32.1 \\
S18 & 9.1 & 84.0 & 0.2 & 28.8 & 30.5 \\
\hline
\end{tabular}

opposite to the observed behavior of surface runoff. Furthermore, when the reduced irrigated area is replaced with cotton, the amount of groundwater recharge decreases and runoff increases as the area of crop replacement increases. This is because the cotton crop uses less water as compared to the winter wheat-maize crop (S10-S12 and S16S18). However, in S1-S3, groundwater recharge is positively correlated with surface runoff because, as water savings increase, groundwater recharge decreases as the volume of ineffective irrigation water is reduced.

\subsection{Assessment of irrigation management scenarios}

Simulated ET for low-pressure pipes and sprinklers under different crop pattern adjustments are given in table 9. It is apparent that the main factor influencing regional ET is precipitation. Regional ET was higher in wet years as compared to dry years, which could not be altered by improvements in irrigation methods or adjustments to the crop pattern. Regional ET is positively correlated with precipitation. Precipitation not only had a significant impact on ET during the current year, but also had an impact on ET for the following year. For example, in 2004, the regional precipitation was $374.6 \mathrm{~mm}$, which was lower than in 2002 , but the simulated ET in 2004 was larger as compared to
Table 9. Simulated ET for low pressure pipe and sprinkler irrigation using different crop pattern adjustments $(\mathrm{mm})$.

\begin{tabular}{lccccc}
\hline $\begin{array}{l}\text { Precipitation } \\
\text { and scenarios }\end{array}$ & 2002 & 2003 & 2004 & 2005 & Average \\
\hline Pcp & 384.8 & 880.0 & 374.6 & 689.6 & 582.3 \\
S7 & 498.3 & 685.9 & 537.8 & 646.3 & 592.1 \\
S8 & 484.5 & 679.0 & 525.5 & 638.4 & 581.8 \\
S9 & 470.8 & 672.2 & 513.3 & 630.6 & 571.7 \\
S10 & 498.1 & 684.1 & 540.5 & 646.7 & 592.3 \\
S11 & 490.5 & 679.9 & 534.3 & 642.3 & 586.7 \\
S12 & 479.9 & 673.6 & 526.5 & 636.5 & 579.1 \\
S13 & 472.5 & 672.7 & 514.4 & 630.0 & 572.4 \\
S14 & 461.0 & 667.3 & 504.0 & 623.4 & 563.9 \\
S15 & 449.7 & 661.9 & 493.8 & 616.9 & 555.6 \\
S16 & 471.5 & 671.3 & 515.9 & 629.3 & 572.0 \\
S17 & 465.1 & 668.0 & 510.5 & 625.4 & 567.2 \\
S18 & 455.8 & 663.0 & 503.5 & 619.9 & 560.5 \\
\hline
\end{tabular}

2002. The abundant rainfall in 2003 supplemented soil water and groundwater through infiltration, and thus maintained relatively wet regional subsurface conditions. Thus, the regional simulated ET in 2004 was influenced by the high rainfall in 2003 .

Using low-pressure pipe and sprinkler irrigation, when the winter wheat-maize planting area was reduced by $10 \%$, the simulated average ET from 2002 to 2005 was $592.1 \mathrm{~mm}(\mathrm{~S} 7)$ and $572.4 \mathrm{~mm}$ (S13), respectively. When $10 \%$ of the growing area of winter wheat-maize was replaced with cotton, the simulated average ET from 2002 to 2005 was 592.3 (S10) and $572.0 \mathrm{~mm}$ (S16), respectively. This indicates that replacing $10 \%$ of the growing area of winter wheat-maize with cotton did not consume significantly more water than simply reducing the planting area of winter wheat-maize by $10 \%$, because cultivating cotton results in relatively little ET. However, as the area of the winter wheat-maize planting was further reduced, water savings were substantially larger when the land was left in fallow as compared to being replaced with cotton. Despite these findings, reducing the winter wheat-maize planting area would inevitably affect agricultural income which can be seen in figure 7, thus decreasing the enthusiasm of farmers to employ water-saving techniques. From scenarios S7-S9 and S13-S15, with the gradual reduction of the winter wheat-maize planting area, the yield and monetary value are also reduced proportionately. Selecting the best water management strategy based on the amount of reduced ET in this instance is likely to encounter resistance during 


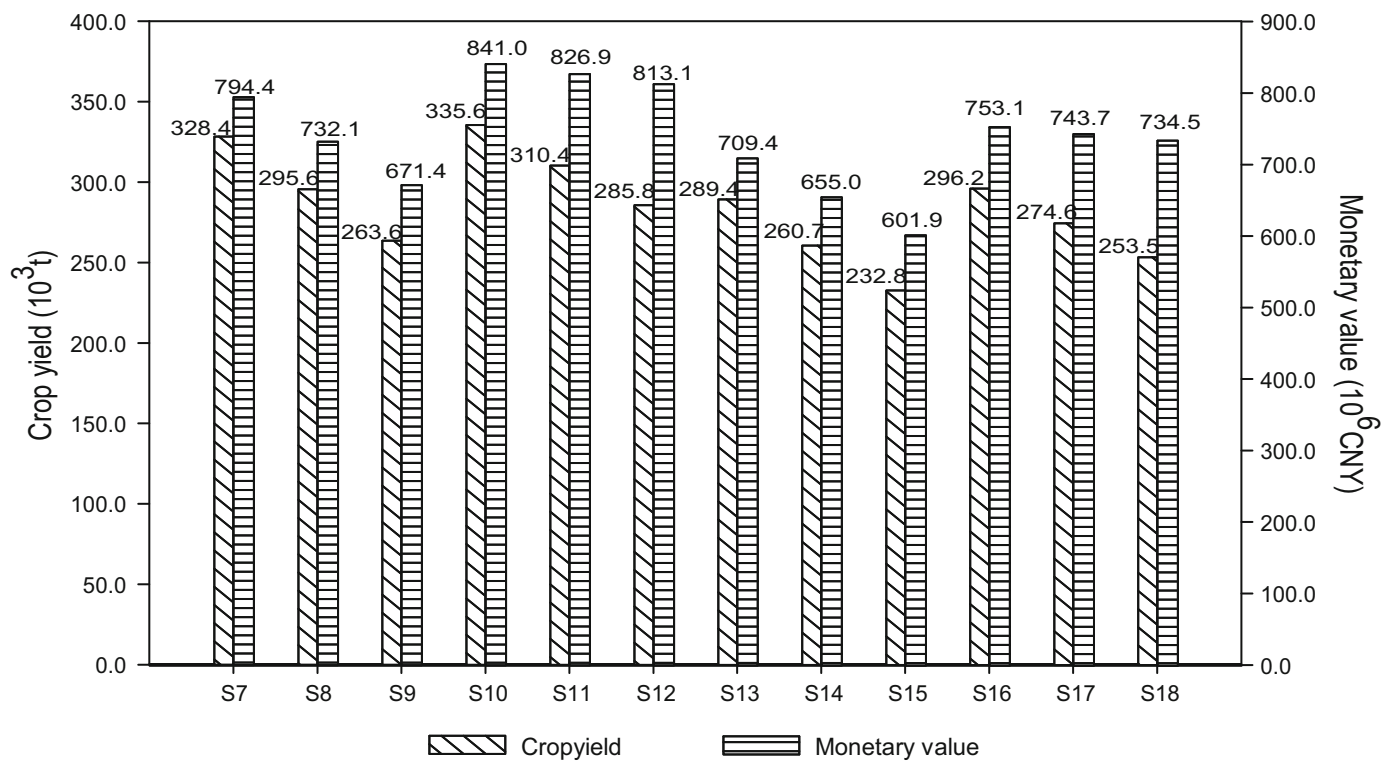

Figure 7. Average crop yield and monetary value of scenarios S7 to S18 in 2002-2005.

implementation. To ameliorate this, we follow the principle of maximizing water savings, while not reducing agricultural income too much, during the selection of the appropriate irrigation management strategies in this study.

\subsection{Regional water management analysis}

Based on precipitation, inflows and outflows, and the amount of water transferred via the SouthNorth Water Transfer Project, target ET for Guantao County was determined to be $566.0 \mathrm{~mm}$ (ignoring domestic and industrial water consumption). The average ET for the county between 2002 and 2005 was $627.9 \mathrm{~mm}$ (Wu et al. 2008), which does not include domestic and industrial ET, and exceeds the target ET by $61.9 \mathrm{~mm}$. To reduce excessive ET, 12 water saving management scenarios (S7-S18) were simulated. A comparison of the simulated ET for low pressure pipe irrigation and sprinkler irrigation using different crop pattern adjustments is shown in figure 8. Six scenarios of crop pattern adjustments were simulated using low pressure pipe irrigation, and these show that low pressure pipe irrigation was not able to save enough water to meet the target ET for Guantao County. For example, in the best water conservation scenario S9, in which the winter wheat-maize cultivated area was reduced by $30 \%$, simulated ET was still $5.7 \mathrm{~mm}$ higher than the target ET. Hence, we conclude from these results that low pressure pipe irrigation is not a suitable water saving measure in Guantao.

Six scenarios of crop pattern adjustments were also simulated using sprinkler irrigation. Results show that simulated ET for S14, S15, and S18 were lower than the target ET level, while simulated ET for S17 was only $0.2 \%$ larger than target ET. Of the models that had simulated ET lower than target ET, S15 was rejected because a reduction of $30 \%$ of the winter wheat-maize planting area would significantly affect agricultural incomes. As shown in figure 7 , the crop yield and income of S15 are $232.8 \times 10^{3} \mathrm{t}$ and $601.9 \times 10^{6} \mathrm{CNY}$, respectively, markedly less as compared to other scenarios. Both S14 and S17 reduced the planting area of winter wheat-maize by $20 \%$, however, S17 replaced the winter wheatmaize with an alternate, low ET crop of cotton, preserving agricultural income levels. Because it did not preserve agricultural income levels, S14 was rejected. When S17 and S18 are compared, S18 has a greater reduction in ET, however it also results in lower crop yield and agricultural income (figure 7). Furthermore, although S18 ensured that the reduction in overall yield and income were not extensive, the scenario is detrimental to regional food security because the planting area, and hence yield, of winter wheat-maize was significantly diminished. As such, S17 was adopted as the best water saving management strategy to achieve regional water resources consumption balance in Guantao. 


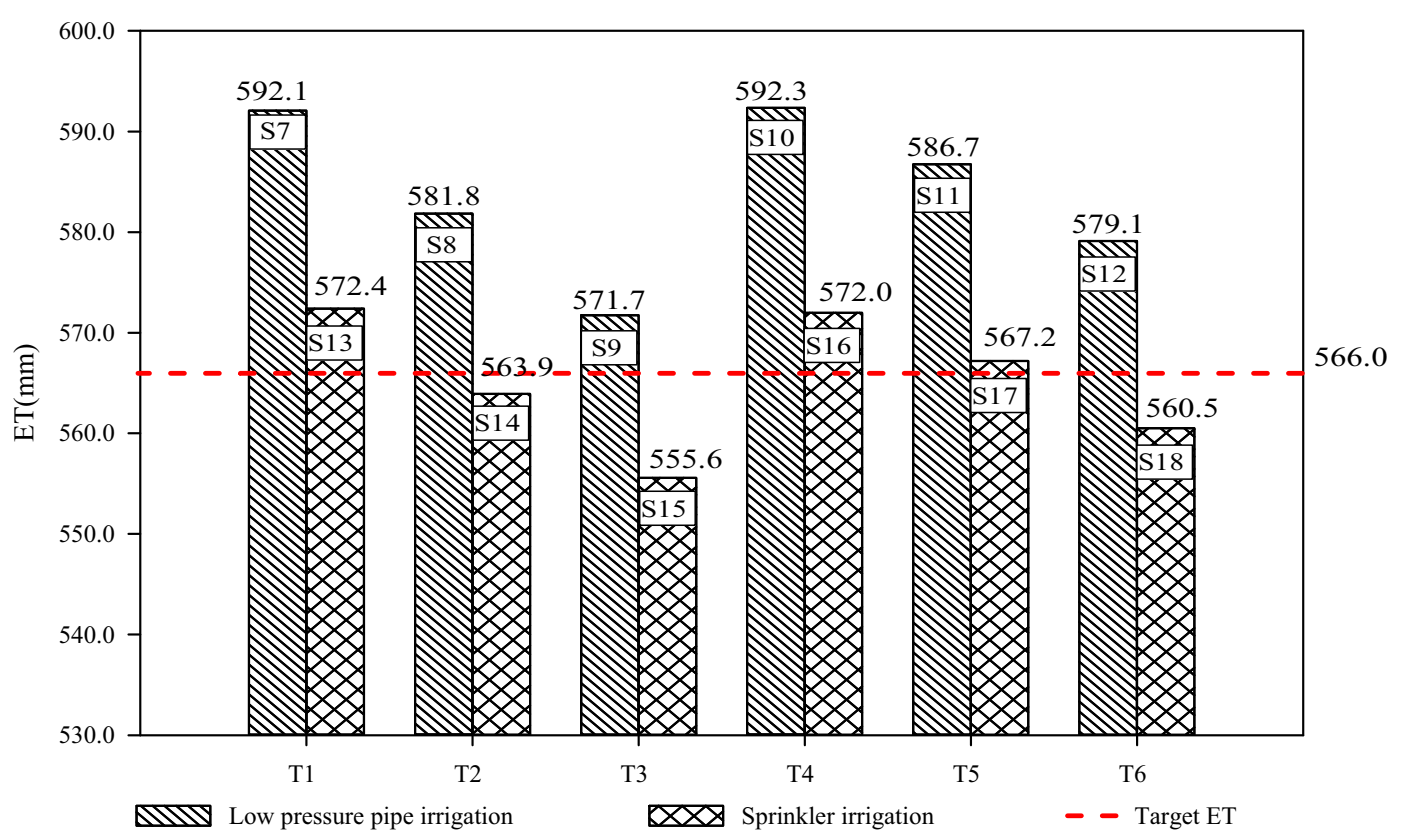

Figure 8. Comparison of simulated ET for low pressure pipe irrigation and sprinkler irrigation under different crop pattern adjustments.

\section{Conclusions}

1. Maintaining water balance as water demand increases is an enormous challenge. Traditional supply and demand management strategies have not achieved this goal based on practical experience. The concept of water consumption balance, which refers to the balance between actual and target ET, converts control of abstractions from surface water and groundwater to water consumption (ET) control, providing a new direction for regional water resource management.

2. The control of regional ET is complex, involving water conservation across many aspects of water use, including domestic, industrial, environmental, and agricultural. However, water consumption for domestic, industrial, and environmental applications is not easy to manage, and consequently, meeting target ET through water conservation in agriculture is critical.

3. The SWAT model can assess changes to ET using various irrigation methods and crop pattern adjustments, and is a valuable tool for investigating ET management. SWAT model parameters can be determined by remote sensing of ET, which in turn provides a means to verify the model.

4. Precipitation is the predominant factor affecting regional ET. Because precipitation during the winter wheat growing season is much less than during the maize growing season, the winter wheat is more dependent on irrigation. Thus, the irrigation of winter wheat has a larger influence on ET as compared to that of maize. Consequently, reducing the area of winter wheat cultivation is the most effective way to reduce regional ET in Guantao County.

5. The reduction of ET by adopting water-saving irrigation methods, such as low-pressure pipe irrigation and sprinkler irrigation, is not as promising as the amount of water these methods save on extraction. While water-saving irrigation methods minimize the wastage of water in the transportation process, their impact on reducing ET is insignificant.

6 . It is not appropriate to rely solely on minimizing ET when selecting the best water saving management strategy. To facilitate the support and adoption of water conservation measures by the agricultural community, strategies need to be chosen that benefit farmers in the region. Through comparative analysis of 12 water saving management scenarios, we ultimately recommend scenario S17 as the best water saving management strategy in the study area. Under this scenario, $20 \%$ of the planting area for winter wheat-maize is replaced by cotton, and the current irrigation method is changed to sprinkler irrigation. While S17 simulated ET is $1.2 \mathrm{~mm}$ larger than target ET, it considers the livelihood of the agricultural community. 
7. The estimation of domestic and industrial ET is very difficult when determining actual and target ET levels. To simplify the calculation in this study, domestic and industrial ET were not considered because agricultural water use accounted for approximately $90 \%$ of total water use in the Guantao region. In future research, domestic and industrial ET should be accounted for.

\section{Acknowledgements}

This work was supported by the Science and Technology Project of Hebei Province, China (Grant No. 15227005D) and Scientific Research Project of Hebei Provincial Education Department (QN2016233, ZD2016131). We would like to thank Editage (www.editage.cn) for English language editing.

\section{References}

Abbott M B, Bathurst J C, Cunge J A, O'Connell P E and Rasmussen J 1986 An introduction to the European hydrological system-systeme hydrologique European, 'SHE'. 1: History and philosophy of a physically-based distributed modelling system; J. Hydrol. 87(1-2) 45-59.

Allen R G, Tasumi M, Morse A and Trezza R 2007 Satellitebased energy balance for mapping evapotranspiration with internalized calibration (METRIC)-applications; $J$. Irrig. Drain. Eng. 133(4) 380-394.

Arnold J G, Williams J R, Srinivasan R and King K W 1996 Soil and water assessment tool (SWAT), User's manual. Temple TX USDA, Agriculture Research Service, Grassland, Soil and Water Research Laboratory.

Barnett T P and Pierce D W 2008 When will Lake Mead go dry?; Water Resour. Res. 44 W3201.

Bastiaanssen W G M, Noordman E J M, Pelgrum H and Davids G 2005 SEBAL model with remotely sensed data to improve water-resources management under actual field conditions; J. Irrig. Drain. Eng. 131(1) 85-93.

Beasley D B and Hyggins L F 1995 ANSWERS User's Manual; Chicago U.S. Environmental Protection Agency, 54p.

Beltran J M 1999 Irrigation with saline water: benefits and environmental impact; Agric. Water Manag. 40 183-194.

Beven K J, Calver A and Morris E M 1987 The Institute of Hydrology distributed model. Report No. 98, Institute of Hydrology, Wallingford, UK.

Blanke A, Rozelle S, Lohmar B, Wang J X and Huang J K 2007 Water saving technology and saving water in China; Agric. Water Manag. 87 139-150.

Brooks D B 2006 An operational definition of water demand management; J. Water Resour. Dev. 22(4) 521528.

Cao W, Bowden W B, Davie T and Fenemor A 2009 Modelling impacts of land cover change on critical water resources in the Motueka River catchment, New Zealand; Water Resour. Manag. 23(1) 137-151.

Davenport D C and Hagan R M 1982 Agricultural water conservation in California, with emphasis on the San Joaquin Valley. Tech. Report 10010, Dept. Land, Air, and Water Resour, Univ. Calif. at Davis, Davis, CA, 219p.

Dawadi S and Ahmad S 2013 Evaluating the impact of demand-side management on water resources under changing climatic conditions and increasing population; J. Environ. Manag. 114 261-275.

DeNicola E, Aburizaiza O S, Siddique A, Khwaja H and Carpenter D O 2015 Climate change and water scarcity: The case of Saudi Arabia; Ann. Glob. Health 81(3) 342353.

Falkenmark M and Rockström J 2004 Balancing water for humans and nature: The new approach in ecohydrology; London UK Earthscan.

FAO 2012 Coping with water scarcity: An action framework for agriculture and food security; Water Reports 38, Food Agric. Organ. (FAO), UN, Rome, Italy, 79p.

FAO 2014 AQUASTAT database. Water withdrawal by sector, around 2007. Food Agric. Organ. (FAO), UN, http:// www.fao.org/nr/aquastat.

Forsee W J and Ahmad S 2011 Evaluating urban storm water infrastructure design in response to projected climate change; J. Hydrol. Eng. 16(11) 865-873.

Frederick K D and Major D C 1997 Climate change and water resources; Clim. Chang. 37(1) 7-23.

Gallopín G C 2012 Five stylized scenarios. Global Water Futures 2050, United Nations Educational, Scientific and Cultural Organization (UNESCO), http://unesdoc. unesco.org/images/0021/002153/215380e.pdf.

Gao Y C, Long D and Li Z L 2008 Estimation of daily actual evapotranspiration from remotely sensed data under complex terrain over the upper Chao river basin in North China; Int. J. Remote Sens. 29 3295-3315.

Gardner G T and Stern P C 1996 Environmental problems and human behavior; Boston Mass Allyn \& Bacon, 369p.

Gleick P H 1998 Water in crisis: Paths to sustainable water use; Ecol. Appl. 8(3) 571-579.

Griensven A V 2005 AVSWAT-X SWAT-2005 Advanced Workshop, SWAT 2005, 3rd Int. Conf., Zurich, Switzerland.

Holvoet K, Gevaert V, Griensven A V, Seuntjens P and Vanrolleghem P A 2007 Modelling the effectiveness of agricultural measures to reduce the amount of pesticides entering surface waters; Water Resour. Manag. 21 20272035.

Jury W A and Vaux H J 2006 The role of science in solving the world's emerging water problems; Proc. Natl. Acad. Sci. USA 102 15715-15720.

Moriasi D N, Arnold J G, Van Liew M W, Bingner R L, Harmel R D and Veith T L 2007 Model evaluation guidelines for systematic quantification of accuracy in watershed simulations; Trans. Am. Soc. Agric. Biol. Eng. (ASABE) 50(3) 885-900.

Nash J E and Sutcliffe J V 1970 River flow forecasting through conceptual models. Part I: A discussion of principles; J. Hydrol. 10(3) 282-290.

Neitsch S L, Arnold J G, Kiniry J R and Williams J R 2005 Soil and water assessment tool (SWAT), Theoretical documentation, Version 2005; Grassland, Soil and Water 
Research Laboratory, Agricultural Research Service, Temple, TX, 618p.

Pengra B 2012 The drying of Iran's Lake Urmia and its environmental consequences, United Nations Environmental Programme (UNEP), Global Environmental Alert Service (GEAS) Bulletin, http://na.unep.net/geas/ getUNEPPageWithArticleIDScript.php?article_id=79.

Perry C, Steduto P, Allen R G and Burt C M 2009 Increasing productivity in irrigated agriculture: Agronomic constraints and hydrological realities; Agric. Water Manag. 96 1517-1524.

Ritchie J T 1972 Model for predicting evaporation from a row crop with incomplete cover; Water Resour. Res. 8(5) 1204-1213.

Rockstrom J, Lannerstad M and Falkenmark M 2007 Increasing water productivity through deficit irrigation: Evidence from the Indus plains of Pakistan; Proc. Natl. Acad. Sci. USA 104 6253-6260.

Russell S and Fielding K 2010 Water demand management research: A psychological perspective; Water Resour. Res. 46 W05302, https://doi.org/10.1029/ 2009WR008408.

Santhi C, Arnold J G, Williams J R, Dugas W A, Srinivasan R and Hauck L M 2001 Validation of the SWAT model on a large river basin with point and nonpoint sources; $J$. Am. Water Resour. Assoc. 37(5) 1169-1188.

Singh A, Krause P, Panda S N and Flugel W A 2010 Rising water table: A threat to sustainable agriculture in an irrigated semi-arid region of Haryana, India; Agric. Water Manag. 97(10) 1443-1451.

Su Z B, Yacob A, Wen J and Van Diepen C A 2003 Assessing relative soil moisture with remote sensing data: Theory, experimental validation, and application to drought monitoring over the North China Plain; Phys. Chem. Earth. 28(1-3) 89-101.

Su Z B 2002 The surface energy balance system (SEBS) for estimation of turbulent heat fluxes; Hydrol. Earth Syst. Sci. 6(1) 85-99.

UNESCO 2012 Managing water under uncertainty and risk. The United Nations World Water Development Report 4: World Water Assessment Programme (WWAP); United Nations Educational, Scientific \& Cultural Organisation (UNESCO), Paris, France.
Van Liew M W, Veith T L, Bosch D D and Arnold J G 2007 Suitability of SWAT for the conservation effects assessment project: Comparison on USDA agricultural research service watersheds; J. Hydrol. Eng. 12(2) 173-189.

Vörösmary C J, Green P, Salisbury J and Lammers R B 2000 Global water resources: Vulnerability from climate change and population growth; Science 289(5477) 284288.

Vörösmary C J, McIntyre P B, Gessner M O, Dudgeon D, Prusevich A, Green P, Glidden S, Bunn S E, Sullivan C A, Liermann C R and Davis P M 2010 Global threats to human water security and river biodiversity; Nature 467 $555-561$.

Wang H X, Zhang L, Dawes W R and Liu C M 2001 Improving water use efficiency of irrigated crops in the North China Plain-measurements and modeling; Agric. Water Manag. 48 151-167.

Wang X, Zhang J, Liu J, Wang G, He R, Elmahdi A and Elsawah S 2011 Water resources planning and management based on system dynamics: A case study of Yulin city; Environ. Dev. Sustain. 13(2) 331-351.

Ward F A and Pullido-Velazquez M 2008 Water conservation in irrigation can increase water use; Proc. Natl. Acad. Sci. USA 105(47) 18215-18220.

Wu B, Jiang L, Yan N, Perry C and Zeng H 2014 Basin-wide evapotranspiration management: Concept and practical application in Hai Basin, China; Agric. Water Manag. 145 145-153.

Wu B, Yan N, Xiong J, Bastiaanssen W G M, Zhu W and Stein A 2012 Validation of ETWatch using field measurements at diverse landscapes: A case study in Hai Basin of China; J. Hydrol. 436-437(5) 67-80.

Wu B, Xiong J, Yan N, Yang L and Du X 2008 ETWatch for monitoring regional evapotranspiration with remote sensing; Adv. Water Sci. $19671-678$.

Yang Z P, Lu W X, Long Y Q and Li P 2009 Application and comparison of two prediction models for groundwater levels: A case study in western Jilin Province, China; J. Arid Environ. 73(4-5) 487-492.

Zhang Y Y, Xia J, Liang T and Shao Q X 2010 Impact of water projects on river flow regimes and water quality in Huai River Basin; Water Resour. Manag. 24889 908. 